\title{
Siliceous foam material and its application in post-combustion carbon capture for NGCC plants: effects of aging conditions
}

\author{
Meng $\mathrm{Y}$ ang $^{1}$, Yan $\mathrm{Y}$ uxin ${ }^{1}$, Jiang Peng ${ }^{2}, W u X$ inyun $^{1}$, Sun Cheng-gong ${ }^{3}, W u \mathrm{Tao}^{1,2}$, and Pang Cheng $\mathrm{Heng}^{1 *}$ \\ ${ }^{1}$ Department of Chemical and Environmental Engineering, The University of N ottingham Ningbo China, Ningbo, 315100, PR China \\ ${ }^{2} \mathrm{~N}$ ew M aterials I nstitute, The U niversity of Nottingham Ningbo China, Ningbo, 315042, P. R. China. \\ ${ }^{3}$ Faculty of Engineering, The U niversity of Nottingham, NG 7, 2TU, UK
}

\begin{abstract}
In an effort to reduce the overall energy penalty and capital expenditure associated with carbon capture technologies, a variety of porous solid adsorbents have been developed. The limitations of solid sorbent in large-scale process are related to its $\mathrm{CO}_{2}$ uptake, physicochemical stability, lifecycle, regenerability and operation condition. In this paper, siliceous foam materials were synthesized via a modified microemulsion templating method and functionalized with branched polyethylenimine (PEI). The physical characteristics of synthesized silica adsorbents under different aging conditions were analysed via $\mathrm{N} 2$ sorption analysis and Scanned Electron Microscopy (SEM) morphological analysis. $\mathrm{CO}_{2}$ uptake was evaluated by thermogravimetric analyser (TGA). The results show that $\mathrm{CO}_{2}$ uptake is desirable even under low $\mathrm{CO}_{2}$ partial pressure and is predictable with multiple linear regression (MLR) model in the range of examined materials.
\end{abstract}

\section{Introduction}

$\mathrm{CO}_{2}$ emission from large-scale use of fossil fuels is the key drive to global warming [1]. Even though government policies encourage the transition to a more sustainable energy strategy, fossil fuels still dominate primary energy consumption in the worldwide and it is predicted to remain the mainstay of energy source in the future [2]. Carbon Capture and Storage (CCS) is seen as the only approach to mitigate the $\mathrm{CO}_{2}$ emission while continuing the use of fossil fuels [3]. Post-combustion capture technology, which requires less investment due to the capture system is integrated to the downstream of the existing sites [4] is promoted as a near-term $\mathrm{CO}_{2}$ abatement strategy since electricity generation is not relied on the presence of $\mathrm{CO}_{2}$ capture system.

Innovative $\mathrm{CO}_{2}$ capture technology should keep a beneficial balance between $\mathrm{CO}_{2}$ capture capacity and energy consumption. Solid adsorption is considered as a feasible substitution to mitigate the energy penalty for state-of-art solvent regeneration process. To date, there are a wide range of solid sorbents being investigated for their ability to capture $\mathrm{CO}_{2}$, including zeolites [5], metal-organic framew orks (M OFs) [6] and silica gels [7]. However, the application of these physical sorbents is limited, especially for carbon capture at low $\mathrm{CO}_{2}$ partial pressure.

Previous investigations have demonstrated that amine-modified siliceous materials, either grafting or impregnation, have a great potential in $\mathrm{CO}_{2}$ adsorption. The $\mathrm{CO}_{2}$ uptake, however, is highly depended on the pore structure. For example, $\mathrm{CO}_{2}$ adsorption capacity with $50 \% \mathrm{PEI}$ is approximately $3.18 \mathrm{mmol} / \mathrm{g}$ and 2.03 $\mathrm{mmol} / \mathrm{g}$ in $15 \% \mathrm{CO}_{2} / \mathrm{N}_{2}$ at $75^{\circ} \mathrm{C}$ for SBA- 15 and M CM 41 respectively $[7,8]$. MCF materials, which consists of uniform cells and windows, have a three-dimensional pore system, where the ultralarge cell shape pores (30$50 \mathrm{~nm}$ ) are interconnected by windows with $9-20 \mathrm{~nm}$ in diameter [9]. Therefore, MCF particles have been the most promising siliceous support materials and have attracted wide attentions in structural modification.

For post-combustion $\mathrm{CO}_{2}$ capture, large volume of flue gas requires high adsorption capacity and selectivity to mitigate energy penalty. However, partial pressure of $\mathrm{CO}_{2}$ is even lower in the flue gas from NGCC plants $\left(5 \% \mathrm{CO}_{2} / \mathrm{N}_{2}\right)$ compared to that of coal-fired power plant $\left(15 \% \mathrm{CO}_{2} / \mathrm{N}_{2}\right)$ [10]. Hence, it is worthwhile to promote the sorbents performance, such as $\mathrm{CO}_{2}$ adsorption capacity, thermal stability, tolerance to impurities and adsorption kinetics. In this study, we investigated the impacts of preparation conditions, particularly aging conditions, on the textual properties of synthesized materials and hence their $\mathrm{CO}_{2}$ adsorption performance. Mesoporous silica with large surface area, pore volume and pore size, were synthesized to achieve a higher PEI loading, and the performance as $\mathrm{CO}_{2}$ adsorbents for NGCC plants was evaluated.

\section{Material and methods}

Corresponding author: chengheng.pang@ nottingham.edu.cn 


\subsection{Chemicals}

A Nonionic tri-block copolymer surfactant Pluronic P123 ( M W $\left._{\text {av }}=5800\right)$, hydrochloric acid $(36 \%), 1,3,5$,Trimethyl benzene (TM B), tetraethyl orthosilicate (TEOS, 99.999\%), ammonium fluoride $\left(\mathrm{NH}_{4} \mathrm{~F}, 99.99 \%\right)$, branched polyethyleneimine ( $\left.\mathrm{PEI}, \mathrm{MW}_{\mathrm{av}}=1800\right)$. PQ silica was purchased from PQ Corporation.

\subsection{Modified microemulsion templating method}

The preparation method follows typical route of microemulsion templating reported by Schmidt-Winkel and co-workers[11]. $8 \mathrm{~g}$ of structure directing agent P123 was dissolved in $23.7 \mathrm{~g} \mathrm{HCl}(36 \%)$ and $130 \mathrm{~g}$ deionized (DI) water with continuous stirring at $40^{\circ} \mathrm{C}$ until complete dissolution. Then $8 \mathrm{~g}$ TM B was added and the resulting solution was stirring continuously at $40^{\circ} \mathrm{C}$. A fter 2 hours, $18.4 \mathrm{ml}$ of TEOS was added and stirred for another $5 \mathrm{mins}$. A hydrolysis step occurred and lasted for 20 hours at $40^{\circ} \mathrm{C}$. Thereafter, $9.2 \mathrm{mg} \mathrm{N} \mathrm{H}_{4} \mathrm{~F}$ dissolved in $10 \mathrm{~g}$ deionized water and added to the mixture. The second stage of aging will carried out at $70^{\circ} \mathrm{C}, 80^{\circ} \mathrm{C}, 90$ ${ }^{\circ} \mathrm{C}, 100^{\circ} \mathrm{C}$ under a static conditions for $15 \mathrm{hrs}, 24 \mathrm{hrs}$, $42 \mathrm{hrs}$ and $53 \mathrm{hrs}$, respectively. The white precipitate was isolated by vacuum filtration and washing with warm DI water. The wet precipitate dried in fume cupboard and calcined in air at $550^{\circ} \mathrm{C}$ for 8 hours in muffle furnace to obtain final product. The synthesis route is shown in Scheme 1.

\subsection{PEI impregnation}

PEI loading describes the weight percentage of branched PEI in the impregnated adsorbents as shown in the Eq. (1). The weighted PEI was dissolved in $10 \mathrm{ml}$ water with vigorous stirring. After $15 \mathrm{mins}$, calcined silica was gradually poured into the solution. The mixture was stirred overnight at room temperature and then the amine-impregnated adsorbents were dried at $40^{\circ} \mathrm{C}$ in a vacuum oven for 24 hours. The impregnated adsorbents were collected for further testing.

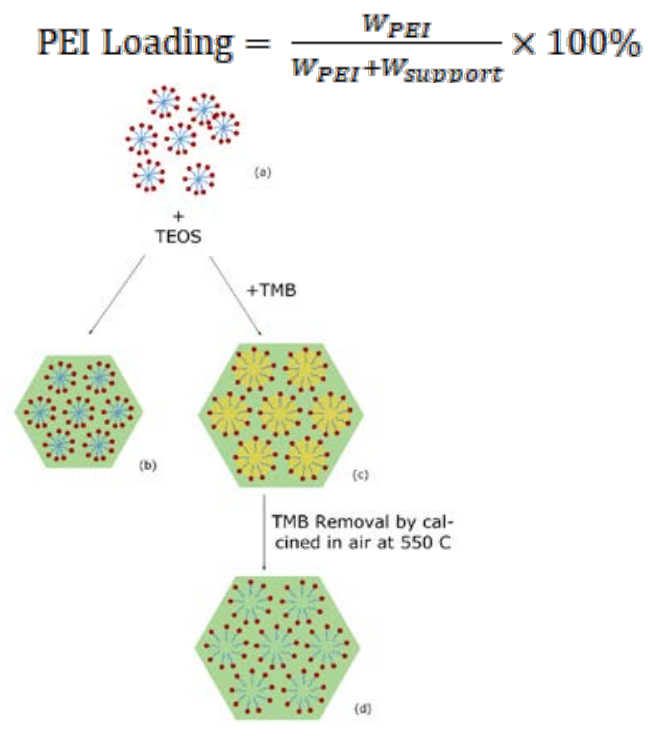

Scheme 1 A typical synthesis route of MCF materials compared to SBA-15.

\subsection{Characterisation of silica adsorbents}

The nitrogen adsorption-desorption isotherms of silica were examined at 77K with Micromeritics A SA P 2420. The silica was degassed at $120^{\circ} \mathrm{C}$ for 12 hours before analysis. Surface area values were determined by the B runauer-Emmett-Teller (BET) equation. In addition, the mesopore volume and micropore volume of the silica were determined using the Barrett-J oyner-Halenda $(\mathrm{BJ} H)$ method and t-plot equation. The foam materials were coated with gold and the morphology of the sample were obtained using a Zeiss Sigma VP Scanned Electron Microscopy (SEM).

\section{5. $\mathrm{CO}_{2}$ uptake}

The $\mathrm{CO}_{2}$ adsorption capacity of the adsorbents was examined by thermogravimetric analyser (Netzsch STA 449F3, German). Prior to adsorption experiment, the sample (15-20mg) was preheated to remove any moisture or pre-captured gas by keeping isothermal at $110^{\circ} \mathrm{C}$ under a nitrogen flow of $50 \mathrm{ml} / \mathrm{L}$ and then the temperature was set to adsorption temperature which is $75^{\circ} \mathrm{C}$. With the aim of testing the availability of PEI impregnated silicas for NGCC power plants, the $\mathrm{CO}_{2}$ adsorption experiments were implemented with a simulated gas stream of $5 \% \quad \mathrm{CO}_{2} / \mathrm{N}_{2}$ (partial pressure $0.05 \mathrm{bar}$ ). Each adsorption process keeps isothermal for 60 mins to achieve adsorption equilibrium at $75^{\circ} \mathrm{C} \cdot \mathrm{CO}_{2}$ uptake was determined through the weight difference between initial dry mass and mass after adsorption as shown in Eq. (2).

$$
\mathrm{CO}_{2}=\frac{W_{\text {final }}-W_{\text {initial }}}{W_{\text {initial }}} \times 100 \%
$$

\section{Results and discussion}

3.1. Morphological and pore structural characterisation of synthesized MCF particles

Table 1. A ging conditions and textual properties for PQsilica and synthesised M CF particles.

\begin{tabular}{|c|c|c|c|c|c|c|c|}
\hline Sample & $\begin{array}{l}\text { Aging } \\
\text { Time } \\
\text { (hrs) }\end{array}$ & $\begin{array}{l}\text { Aging } \\
\text { Temp. } \\
\left.{ }^{\circ} \mathrm{C}\right)\end{array}$ & $\begin{array}{c}\text { Surface } \\
\text { Area } \\
\left(\mathrm{m}^{2} / \mathrm{g}\right)\end{array}$ & $\begin{array}{c}\text { Pore } \\
\text { Volume } \\
\left(\mathrm{cm}^{2} / \mathrm{g}\right)\end{array}$ & $\begin{array}{l}\text { Pore } \\
\text { size } \\
(\mathrm{nm})\end{array}$ & $\begin{array}{c}\text { Cell } \\
\text { diameter } \\
(\mathrm{nm})\end{array}$ & $\begin{array}{c}\text { Windows } \\
\text { diameter } \\
(\mathrm{nm})\end{array}$ \\
\hline PQ-silica & - & - & 269.4 & 1.4 & 30.0 & 24.7 & 18.6 \\
\hline MCF- $70-24$ & 24 & 70 & 629.3 & 1.4 & 13.0 & 12.7 & 6.1 \\
\hline MCF-80-24 & 24 & 80 & 558.1 & 1.6 & 15.0 & 15.3 & 7.8 \\
\hline MCF-90-24 & 24 & 90 & 492.7 & 1.7 & 17.0 & 16.7 & 10.8 \\
\hline MCF-100-15 & 15 & 100 & 571.4 & 2.0 & 18.0 & 17.9 & 8.6 \\
\hline MCF-100-24 & 24 & 100 & 554.7 & 2.1 & 19.0 & 19.4 & 11.0 \\
\hline MCF-100-42 & 42 & 100 & 544.0 & 2.7 & 23.0 & 23.1 & 13.4 \\
\hline MCF-100-53 & 53 & 100 & 451.3 & 2.1 & 22.0 & 22.0 & 15.1 \\
\hline
\end{tabular}

Fig. 1 shows the surface morphologies of commercial PQ-silica and representative spherical foams synthesised at different aging conditions. As shown in Fig. 1(a) and (d), due to the formation of spherical TTMB/P123f droplets [9], the tubular siliceous foams experience a T"Cylindrical-to-spherical $\int$ transition, which illustrate the significant increment in pore volume of M CFs as shown in Table 1. In Fig. 1(b) and (c), excessive aggregation of 
particles with different sizes is observed in either lower aging temperature $\left(70^{\circ} \mathrm{C}\right)$ or limited aging time (15hr). The cluster-like morphologies are somewhat similar to highly-packed disordered PQ-silica ${ }^{[12]}$. With the increasing of aging temperature from $70^{\circ} \mathrm{C}$ to $100^{\circ} \mathrm{C}$, the particles become larger, more uniform and isolated. W ith regards to aging temperature, the initial transition follows the same trend as that of aging temperature. However, the aggregation of isolated spherical micelles occurs when aging time increased to 42 hours. When further increasing the aging time to 53 hours, the formation of significantly larger cucurbit-like spherical structure is observed, which implies that the small particles were re-dissolved and aggregated on large particles.

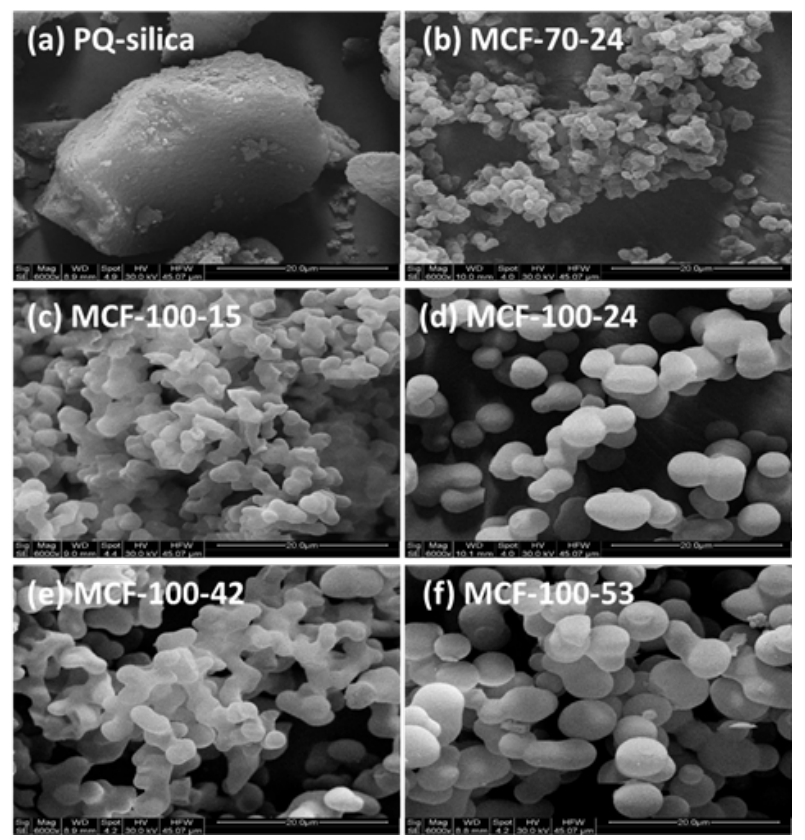

Fig. 1. SEM images of $P Q$-silica and M CF particles synthesized with different conditions. (a) PQ-silica; (b) M CF70-24 was aging at $70{ }^{\circ} \mathrm{C}$ for 24 hours; (c) M CF-100-15 was aging at 100 oC for 15hours; (d) M CF-100-24 was aging at 100 OC for 24hours; (e) M CF-100-42 was aging at $100^{\circ} \mathrm{C}$ for 42 hours; (f) M CF-100-53 was aging at 100 oC for 53 hours.

The $\mathrm{N}_{2}$ adsorption/desorption isotherms in Fig. 2 are classified as Type IV with steep hysteresis loop, which is typical for a well-defined mesoporous structure [13-15]. In Fig. 2(a) and (b), M CF-100-24 achieved a higher $\mathrm{N}_{2}$ adsorption than $\mathrm{PQ}$-silica by adding TMB, as also evidenced by SEM images in Fig. 2. Meanwhile, the hysteresis loop of $\mathrm{PQ}$-silica shifted to higher relative pressure region compared with MCF-100-24, which indicts larger pore size. Hysteresis loops of Type $\mathrm{H} 1$ indicates a cylinder shaped pores interconnected with narrow windows as shown in Fig. 2(a), 2(b) and 2(d), while the hysteresis loop in Fig. 2(c) tends to be a H2 type that the pore structure is composed of a combination of cylinder and sphere, which implies incomplete transition to spherical structure due to the limited aging time. The analytical results from nitrogen sorption is consistent with observation of SEM, which illustrate the pore shape is ink-bottle-type [16]. The isotherms in Fig. 2 illustrate that both MCF and modified MCF adsorbents have a more promising substructure than commercial PQ-silica in terms of surface area and pore volume (Table 1). The utilization of TMB brings a phase transformation from highly ordered 1D cylindrical structure to a continuous 3D pore system which comprises uniform spherical cell cavities with identical windows that can further expedite the access to the cavities [9].

(a)

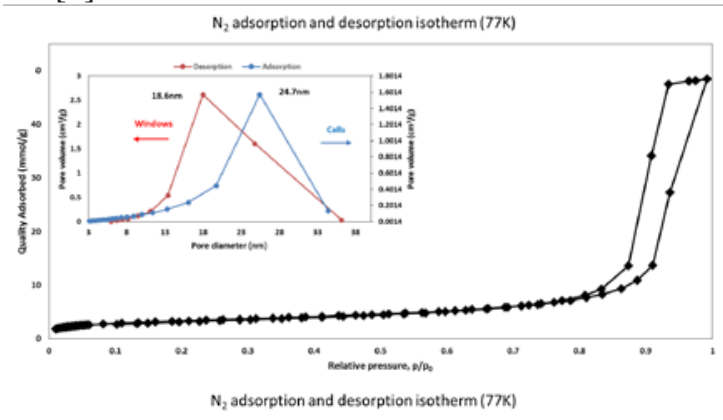

(b)

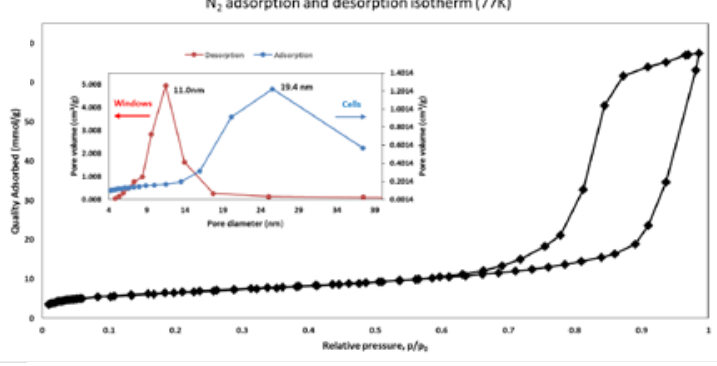

(c)

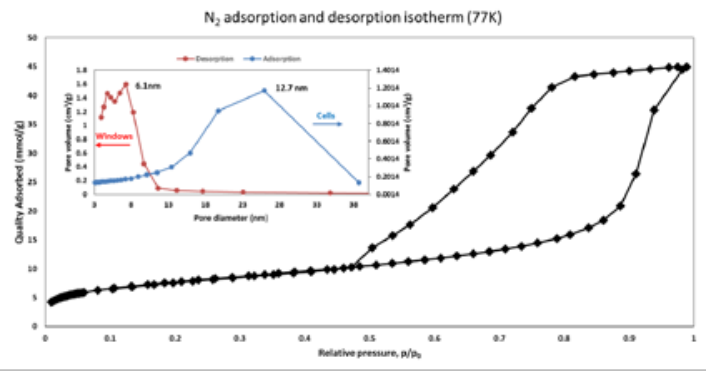

(d)

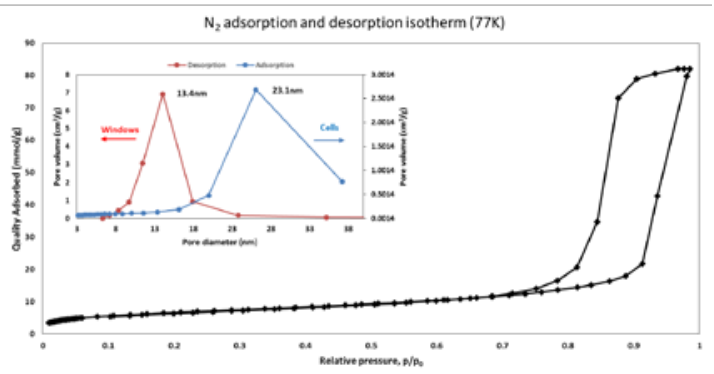

Fig. 2. Nitrogen adsorption/desorption isotherms and corresponding pore size analyses for (a) PQ -silica; (b) M CF100-24; (c) M CF-70-24 and (d) M CF-100-42 based on a Barret-J oyner-Halenda (BJH) method.

\subsection{CO2 adsorption performance}

Herein, commercial PQ-silica was used as a baseline to evaluate the $\mathrm{CO}_{2}$ adsorption performance of synthesized MCFs in this study. As shown in Fig. 3, all PEI-modified MCFs exhibit a higher $\mathrm{CO}_{2}$ uptake than that of commercial PQ-silica. Due to the limited pore volume, the PEI loading of PQ-silica is only $40 \mathrm{wt} \%$, while the MCF particles could achieve 70 wt\% PEI loading. The MCF-100-42 achieved highest $\mathrm{CO}_{2}$ uptake 
of $(16.6 \mathrm{wt} \%)$ due to its largest pore volume $\left(2.7 \mathrm{~cm}^{3} / \mathrm{g}\right)$ with cell cavity diameter $(23.1 \mathrm{~nm})$ as presented in Table 1. Additionally, the results also show that $\mathrm{CO}_{2}$ uptakes varies even under the same PEI loading. This suggests that porous framework of MCF particles has a significantly influence on the mobility of PEI molecules and hence accessibility of $\mathrm{CO}_{2}$ within PEI threshold [17, 18]. Although the barrier of $\mathrm{CO}_{2}$ could be overcome by increasing the adsorption temperature, cycling stability under high adsorption temperature is challenging for PEI-modified adsorbents.

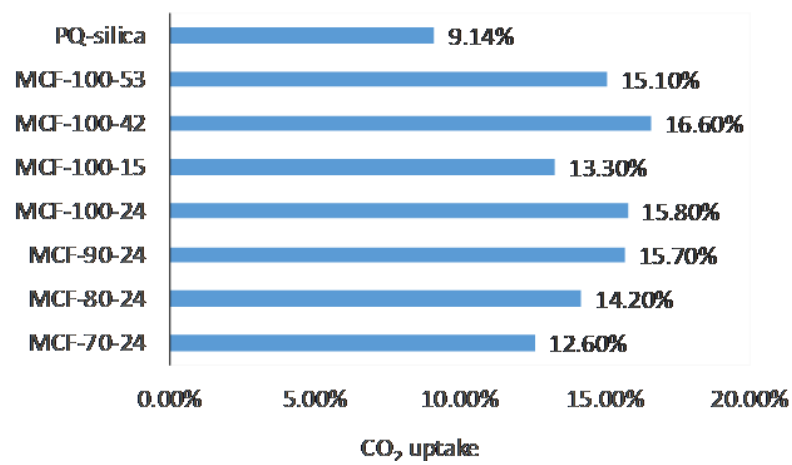

Fig. 3. A comparison of $\mathrm{CO}_{2}$ uptakes (wt\%) of PQ-silica (40wt\%PEI) and all synthesised samples (70wt $\% \mathrm{PEI})$ at $75^{\circ} \mathrm{C}$ $\& 5 \% \mathrm{CO}_{2}$ in $\mathrm{N}_{2}$.

As discussed above, the $\mathrm{CO}_{2}$ adsorption capacity is highly depended on pore structure of MCFs, whilst the pore structure could be described by pore volume, pore size, window size and BET surface area. Therefore, it would be beneficial if the $\mathrm{CO}_{2}$ uptake could be predicted with the parameters above, which in turn, will guide the design of porous framework. In the present work, a multiple linear regression is established via L evenberg$M$ arquardt training algorithm to investigate how the pore volume $\left(X_{v}\right)$, pore size $\left(X_{S}\right)$ and window size $\left(X_{w}\right)$ relate to $\mathrm{CO}_{2}$ adsorption capacity $(\mathrm{Y})$. The prediction model ( $\mathrm{R}$-squared is 0.98 ) is shown in Eq. (3), whilst the results given in Fig. 4 shown that prediction model is the model agrees well with the experimental data and vice versa.

$Y=0.1903+0.1039 X_{v} \pm 0.0219 X_{s}+0.0149 X_{w}$ Eq. (3)

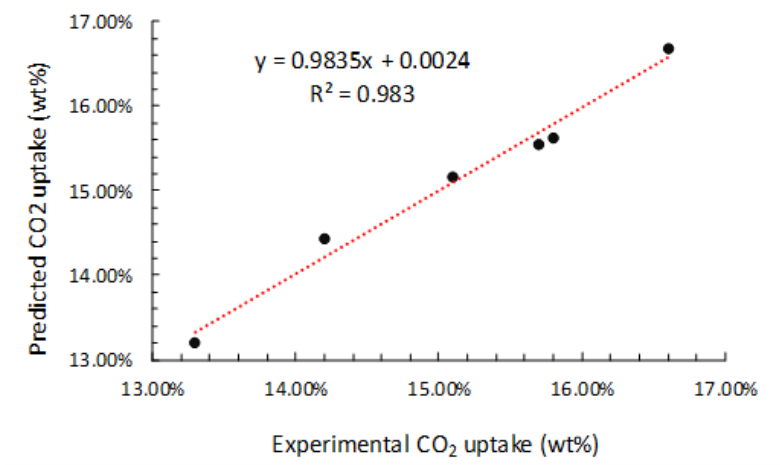

Fig. 4. Plot of $\mathrm{CO}_{2}$ uptake from experimental analysis against the predicted value.

\section{Conclusion}

The effects of aging conditions on the pore structure of spherical meso-structured siliceous foam materials were investigated. This work demonstrated that the 3D porous framework is tunable with different aging conditions without the addition of any chemicals. The pore volume of synthesized material ranges from 1.4 to $2.7 \mathrm{~cm}^{3} / \mathrm{g}$, whilst pore size is in the range between $13 \mathrm{~nm}$ to $23 \mathrm{~nm}$. In general, higher aging temperature and longer aging period could enhance the growth of cell cavity. In this study, all pore-expanded M CF adsorbents exhibit a higher $\mathrm{CO}_{2}$ adsorption capacity than that of baseline PQsilica (SBA-15) with 40wt\% PEI loading. The highest $\mathrm{CO}_{2}$ uptake is $16.6 \%$ which is achieved by MCF-100-42 with 70 wt $\%$ PEI loading. M oreover, the $\mathrm{CO}_{2}$ uptake of MCF materials is predictable with its pore volume, window size and pore size. This finding could facilitate the design of pore structure to further improve the $\mathrm{CO}_{2}$ adsorption performance.

The author acknowledges the financial support from the International Doctoral Innovation Centre, Ningbo Education Bureau, Ningbo Science and Technology Bureau, and the University of Nottingham. This work was also supported by Ningbo Natural Science Programme (Project code: 2018A 610069), Ningbo ${ }^{T} S \& T$ innovation 2025 (Major Programme (Project code: 2018B 10022) and UNNC FOSE Faculty Inspiration G rant China.

\section{References}

1. Bernstein, L., et al., Climate Change 2007: Synthesis Report., in International Panel on Climate Change. 2007: Cambridge U niversity Press.

2. Schwartz, S.E., Uncertainty in climate sensitivity: Causes, consequences, challenges. Energy \& Environmental Science, 2008. 1(4): p. 430-453.

3. Nijnik, M., Chapter 8 Carbon Capture and Storage in Forests, in Carbon Capture: Sequestration and Storage. 2009, The Royal Society of Chemistry. p. 203-239.

4. Herzog, H., J. Meldon, and A. Hatton, Advanced Post-Combustion $\mathrm{CO}_{2}$ Capture. 2009.

5. Akhtar, F., et al., Colloidal processing and $\mathrm{CO}_{2}$ capture performance of sacrificially templated zeolite monoliths. A pplied Energy, 2012. 97(0): p. 289-296.

6. Lv, X., et al., High $\mathrm{CO}_{2} / \mathrm{H}_{2}$ and $\mathrm{CO}_{2} / \mathrm{CH}_{4}$ selectivity in a chiral metal-organic framework with contracted pores and multiple functionalities. Chem Commun, 2014(52(2014)): p. pp. 6886-6889.

7. Y u, C.H., C.H. Huang, and C.S. Tan, A Review of CO2 Capture by Absorption and Adsorption. A erosol and A ir Quality Research, 2012.

8. Wang, X., et al., Molecular basket sorbents polyethylenimine-SBA-15 for $\mathrm{CO}_{2}$ capture from flue gas: Characterization and sorption properties. Microporous and Mesoporous Materials, 2013. 169(0): p. 103-111. 
9. Schmidt-Winkel, P., et al., Mesocellular Siliceous Foams with Uniformly Sized Cells and windows. J. A m. Chem. Soc, 1999(121, 254-255).

10. BP, BP Energy Outlook 2035 January 2014. 2014: L ondon, U nited Kingdom.

11. Schmidt-W inkel, P., et al., Microemulsion Templating of Siliceous Mesostructured Cellular Foams with Well-Defined Ultralarge Mesopores. Chem. M ater, 2000(12, 686-689).

12. $\mathrm{Y}$ an, $\mathrm{X}$., et al., Amine-modified mesocellular silica foams for $\mathrm{CO}_{2}$ capture. Chemical Engineering Journal, 2011. 168(2): p. 918-924.

13. Bansal, R.C. and M. Goyal, Activated Carbon A dsorption. 2005: Taylor \& Francis.

14. Thommes, M., Physical Adsorption Characterization of Nanoporous Materials. Chemie Ingenieur Technik, 2010. 82(7): p. 1059-1073.
15. Sing, K.S.W., et al., Reporting physisorption data for gas/solid systems with special reference to the determination of surface area and porosity (Recommendations 1984). Pure and Applied Chemistry, 1985. 57: p. 603-619.

16. Gregg, S.J. and K.S.W. Sing, Adsorption, Surface Area and Porosity. Second ed. 1982, San Diego: A cademic Press Inc.

17. M onazam, E.R., J. Spenik, and L.J. Shadle, CO2 desorption kinetics for immobilized polyethylenimine (PEI). Energy \& Fuels, 2013. 28(1): p. 650-656.

18. Zhang, Z., et al., Enhancing sorption performance of solid amine sorbents for CO2 capture by additives. Energy Procedia, 2013. 37: p. 205-210. 